\title{
Shox2 is required for the proper development of the facial motor nucleus and the establishment of the facial nerves
}

\author{
Jessica M Rosin ${ }^{1}$, Deborah M Kurrasch ${ }^{2+}$ and John Cobb ${ }^{1 *+}$
}

\begin{abstract}
Background: Axons from the visceral motor neurons (vMNs) project from nuclei in the hindbrain to innervate autonomic ganglia and branchial arch-derived muscles. Although much is known about the events that govern specification of somatic motor neurons, the genetic pathways responsible for the development of vMNs are less well characterized. We know that vMNs, like all motor neurons, depend on sonic hedgehog signaling for their generation. Similarly, the paired-like homeobox 2b (Phox2b) gene, which is expressed in both proliferating progenitors and postmitotic motor neurons, is essential for the development of vMNs. Given that our previous study identified a novel role for the short stature homeobox 2 (Shox2) gene in the hindbrain, and since SHOX2 has been shown to regulate transcription of islet $1(\mid / / 1)$, an important regulator of $\mathrm{vMN}$ development, we sought to determine whether Shox 2 is required for the proper development of the facial motor nucleus.

Results: Using a Nestin-Cre driver, we show that elimination of Shox2 throughout the brain results in elevated cell death in the facial motor nucleus at embryonic day 12.5 (E12.5) and E14.5, which correlates with impaired axonal projection properties of $\mathrm{vMNs}$. We also observed changes in the spatial expression of the $\mathrm{vMN}$ cell fate factors $/ s / 1$ and Phox2b, and concomitant defects in Shh and Ptch1 expression in Shox2 mutants. Furthermore, we demonstrate that elimination of Shox 2 results in the loss of dorsomedial and ventromedial subnuclei by postnatal day 0 (P0), which may explain the changes in physical activity and impaired feeding/nursing behavior in Shox2 mutants.
\end{abstract}

Conclusions: Combined, our data show that Shox 2 is required for development of the facial motor nucleus and its associated facial (VII) nerves, and serves as a new molecular tool to probe the genetic programs of this understudied hindbrain region.

Keywords: Short stature homeobox 2 (Shox2) gene, Islet 1 (Is/1), Sonic hedgehog (Shh), Visceral motor neurons (vMNs), Facial motor nucleus, Facial (VII) nerves

\section{Background}

In the hindbrain, motor neuron progenitors are born in a region-specific manner, neighboring the floor plate, in response to their level of exposure to different morphogenetic gradients $[1,2]$. These neuronal progenitors differentiate in a rhombomere-specific pattern, which requires the correct spatiotemporal expression of the

\footnotetext{
*Correspondence: jacobb@ucalgary.ca

†Deborah M Kurrasch and John Cobb contributed equally to this work

${ }^{1}$ Department of Biological Sciences, University of Calgary, 2500 University

Drive N.W., BI286D, Calgary, AB T2N 1N4, Canada

Full list of author information is available at the end of the article
}

homeotic (Hox) gene clusters [3-6]. Motor neuron progenitors in the hindbrain can differentiate into somatomotor neurons (sMNs), which innervate the skeletal muscles of the body, or visceromotor neurons (vMNs), which innervate autonomic ganglia (general vMNs) and branchial arch-derived muscles (special vMNs) $[3,7,8]$. Facial (VII) motor neurons, which originate from rhombomeres $4 / 5$, belong to the vMN class of motor neurons. At embryonic day 11.25 (E11.25), facial motor neurons begin to migrate caudally to the pial side of the hindbrain to form the facial motor nucleus, which subsequently segregates into two lobes $[6,9,10]$. Despite the elucidation of the genetic mechanisms that specify sMN identity, 
the corresponding pathways responsible for the establishment of vMNs are less well understood. Furthermore, even though sonic hedgehog $(\mathrm{SHH})$ signaling is known to be required for the development of all motor neurons [7, 11-15], the upstream regulators of Shh expression and function during late embryonic and early postnatal development, especially within the vMNs of the facial motor nucleus, remain largely unknown [16].

The paired-like homeobox 2b $($ Phox $2 b)$ gene is expressed in both proliferating progenitors and postmitotic motor neurons and is required for the development of vMNs [17, 18]. Similarly, the homeodomain transcription factor islet1 (ISL1), which is expressed in both post-mitotic sMNs and vMNs, plays a broad role in motor neuron identity and specification $[7,8,17,19$, $20]$. In the absence of $I s l 1$, mice die during embryogenesis around E11.5. This embryonic lethality is associated with an increase in cell death in the hindbrain and neural tube, suggesting that loss of Isl1 function results in the death of cells that were fated to differentiate into motor neurons [19]. In the trigeminal and dorsal root ganglia (DRG), Isl1 appears to play distinct roles during early (i.e. neurogenesis) versus late (i.e. subtype specification) development [21]. In cranial ganglia, Isl1 is required for cell survival and Isl1 mutants show thinner blunted facial (VII) ganglia [22]. However, the precise role of Isl1 in these cell types and in their respective hindbrain nuclei, such as the facial motor nucleus, remains poorly documented.

The adult facial motor nucleus contains seven subnuclei; the lateral, dorsolateral, dorsal intermediate, ventral intermediate, dorsomedial and ventromedial nuclei are located within the main nucleus, while the seventh, the dorsal accessory nuclei, is located above the main nucleus $[23,24]$. Neurons innervating the nasolabial musculature are located in the lateral facial motor nucleus, while neurons supplying the auricular musculature are located in the medial facial motor nucleus $[23,24]$. Together the lateral, intermediate and medial subnuclei comprise 43, 27.1 , and $28.7 \%$, respectively, of the motor neurons in the adult facial motor nucleus, with the dorsal accessory nuclei contributing the final 1.2\% [23].

Studies with mouse knockout models have shown that Shox2 is required for normal development of the humerus and femur [25-27], the anterior palate [28], the temporomandibular joint of the jaws [29], the sinoatrial valves and pacemaker region of the heart [30, 31], and TrkB-positive mechanosensory neurons of the dorsal root ganglia [32]. Most recently, Shox 2 has been shown to play an important role in development of the inferior colliculus and cerebellum [33]. We suspected a function for Shox2 during facial motor nucleus development given our previous study demonstrating a novel role for Shox 2 in the hindbrain [33], and since SHOX2 has been shown to regulate transcription of $I s l 1$ [34], an important regulator of vMN development [7, 8, 19, 22]. In the current study we show that conditional inactivation of Shox2 in the brain results in impaired axonal projections of vMNs and a concomitant loss of medially located neurons in the facial motor nucleus postnatally. Furthermore, we demonstrate that Shox2-mutant neonates display impaired feeding behavior, perhaps due to facial paralysis as a result of improper development and function of the facial nerves.

\section{Results}

\section{Shox 2 expression in the face and facial motor nucleus during development}

Whole-mount in situ hybridization (WISH) at E11.5 showed Shox2 expression in the trigeminal (V) and facial (VII) ganglia, in addition to the developing maxillary process and mandibular arch (Figure 1a). Shox 2 continued to be expressed in the trigeminal (V) ganglia, maxillary process and mandibular arch at E12.5 (Figure 1b). We also visualized the Shox 2 expression pattern with a novel Shox $2^{\text {lacz }}$ allele (described in "Methods"). X-gal staining of embryos carrying the Shox $2^{\text {lacz }}$ allele accurately reproduced the endogenous Shox2 expression pattern with increased sensitivity and less background compared to WISH (Additional file 1: Figure S1). At E10.5, Shox $2^{\text {lacZ/+ }}$ embryos showed lacZ staining in the trigeminal (V) and facial (VII) ganglia of the embryo (Figure 1f). Similarly at E11.5, lacZ staining was visible in the trigeminal (V) and facial (VII) nerves of the embryo, in addition to the maxillary process and mandibular arch (Figure 1g). LacZ continued to be expressed in the trigeminal (V) ganglion of the embryonic face from E12.5 to E13.5, and could be seen in the developing pharyngeal arch (Figure 1h, i). At E14.5 lacZ expression was present in the facial mesenchyme that contributes to the maxilla and mandible (Figure 1j). However, from E12.5 onward lacZ staining was no longer observed in the facial (VII) ganglia (Figure $1 \mathrm{~h}-\mathrm{j}$ ). Postnatally (P0) lacZ expression was maintained in the facial mesenchyme surrounding the facial (VII) nerves, but not within the axons themselves (Figure 1k). Examination of Shox 2 expression early embryonically in the developing brain showed Shox 2 staining in a region of post-mitotic neurons adjacent to the floor plate (Additional file 2: Figure $\mathrm{S} 2 \mathrm{~A}-\mathrm{B})$, a region where Phox $2 b+/ /$ sl $1+$ are localized (Additional file 2: Figure S2C-E) [18]. Later in the P0 brain, Shox 2 was expressed in the facial motor nucleus (Figure 1c-e). Similarly, in Shox $2^{\text {lacZ/+ }}$ animals, lacZ staining was strongly expressed in both the lateral and medial lobes of the facial motor nucleus (Figure 11-o); however, staining was not visible within the trigeminal nucleus (Figure 1n, arrowhead). 


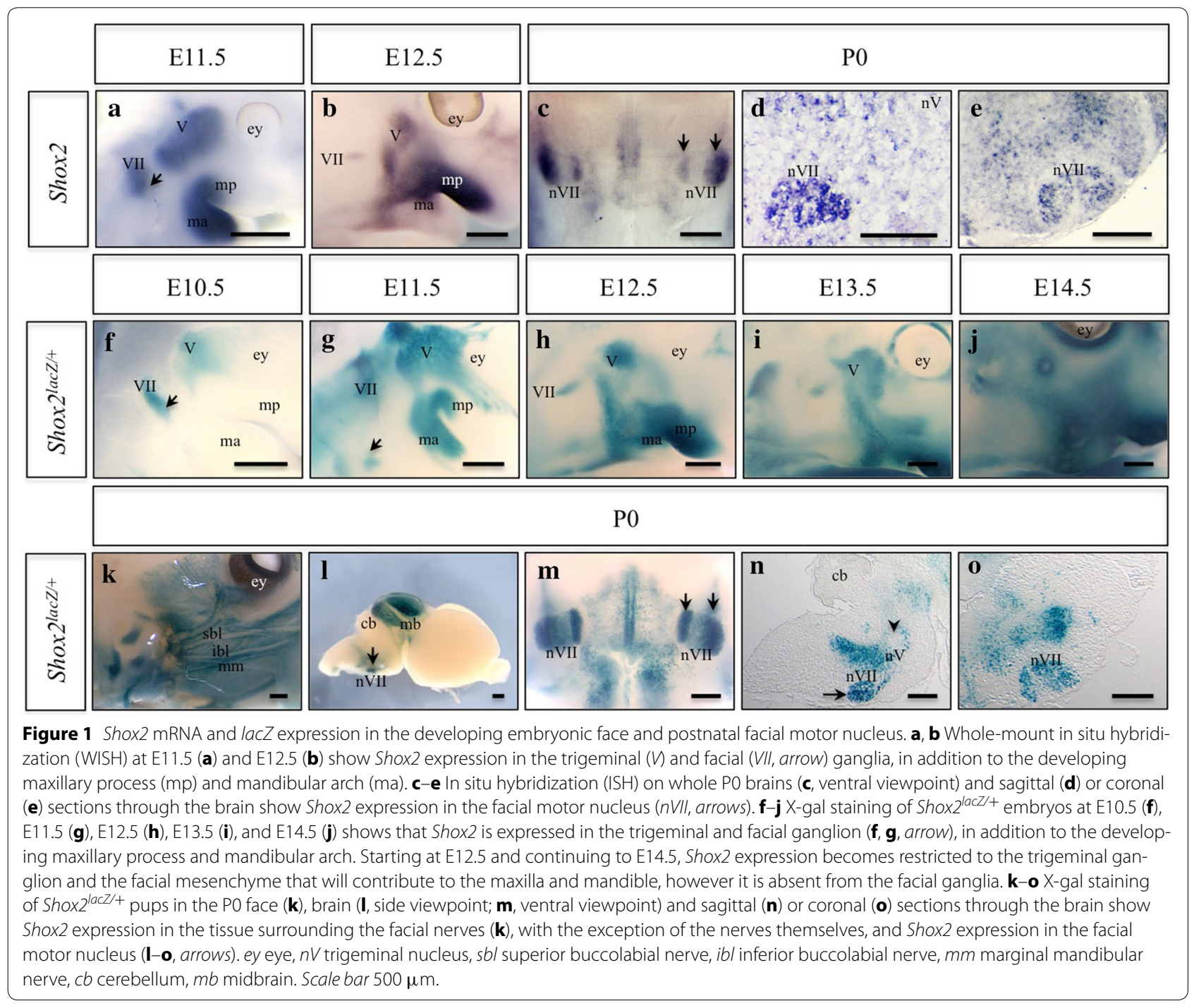

\section{Nestin-Cre Shox2-mutant pups exhibit defects in feeding behavior}

To determine the functional role of Shox 2 in the facial motor nucleus, we used Nestin-Cre [35] to delete the Shox 2 gene conditionally in neural tissue throughout the central nervous system (CNS). We crossed NestinCre; Shox $2^{+/-}$mice with Shox $2^{\text {flox/flox }}$ mice [25] to obtain conditional mutant Nestin-Cre; Shox $2^{\text {flox/- }}$ embryos and neonates. Shox 2 expression was eliminated in the brain of Nestin-Cre Shox2-mutant embryos, including the facial motor nucleus (Additional file 3: Figure S3CD, dashed-circle). All Nestin-Cre Shox2-mutant pups died between 18 to $26 \mathrm{~h}$ following birth. This limited our characterization of Shox 2 function to embryonic and neonatal stages. P0 Nestin-Cre; Shox $2^{\text {flox/- }}$ mutant pups displayed reduced activity and impaired feeding behavior as early as $6 \mathrm{~h}$ following birth (Additional file 4: Movie 1), which correlated with a lack of milk in the stomachs of Nestin-Cre; Shox $2^{\text {flox/- }}$ mutant pups (Additional file 3: Figure S3E, arrows). Since Shox2 is required for the proper development of the palate [28], we analyzed the anterior and posterior palate of Nestin-Cre; Shox $2^{\text {flox/- }}$ mutant pups. We did not observe any obvious defects or malformations in the palate of Nestin-Cre; Shox $2^{\text {flox/- }}$ mutant pups (Additional file 3: Figure S3FK), suggesting that the absence of milk in Shox2-mutant neonatal stomachs was not due to cleft palate malformations. Nestin-Cre; Shox $2^{\text {flox/- }}$ mutant pups also displayed tremors 16-26 h following birth (Additional file 4: Movie 1 ), which could be related to defects in neural circuitry or result from a loss of Shox 2 function in other regions of the hindbrain. 


\section{Facial (VII) nerve branching defects in Nestin-Cre Shox2-mutant animals}

Since Shox2-mutant neonates displayed impaired feeding but an apparently normal palate, we hypothesized that Shox 2 mutants fail to nurse properly due to facial paralysis. To test this hypothesis, we first sought to determine if the abnormal feeding behavior resulted from the loss of a subset of axons in the nerves of the face. We stained control and Nestin-Cre Shox2-mutant embryos and P0 heads with the $2 \mathrm{H} 3$ antibody that visualizes nerves by detecting neurofilaments (Figure 2). In E11.5 Nestin-Cre; Sho $x 2^{f l o x /}$ conditional knockout embryos the trigeminal nerves (V) appeared normal (Figure 2a-b, arrowheads). To confirm that the trigeminal nerves $(\mathrm{V})$ were intact even in the complete absence of Shox2, we performed neurofilament staining on E11.75 Shox2-null embryos (Figure $2 \mathrm{c}-\mathrm{d}$, arrowheads) [25]. While the trigeminal nerves $(\mathrm{V})$ remained intact, the facial nerves (VII) were truncated and failed to branch properly in both NestinCre; Shox $2^{\text {flox/- }}$ conditional knockout and Shox2-null embryos (Figure 2a-d, arrows). At E12.5 the facial (VII) nerves continued to be truncated as compared to controls (Figure 2e-h, dashed-box). Neurofilament staining at E12.5 displayed a range in severity of facial (VII) nerve truncation, with Figure $2 \mathrm{f}$ showing the least severe truncation and Figure $2 \mathrm{~h}$ having the most severe truncation we observed among seven embryos. Later at E13.5 (Figure 2i), E14.5 (Figure 2k), and early postnatal (P0; Figure $2 \mathrm{~m}$ ) stages, the zygomatic, superior buccolabial, inferior buccolabial and marginal mandibular nerve branches of the facial (VII) nerve could be seen in controls (Figure 2i, k, m) [36], however these distinct facial (VII) nerve branches were truncated or absent in NestinCre; Sho $x 2^{\text {flox/- }}$ mutant animals (Figure 2j, l, n; arrows). Similar to E12.5, facial (VII) nerve truncation ranged in severity at the later embryonic and early postnatal timepoints analyzed (data not shown). The severity in facial (VII) nerve truncation observed in Nestin-Cre; Shox$2^{f l o x} /-$ mutant animals, displayed in Figure 2j, l, n, are representative of the most common truncations observed.

To confirm the persistent lack of proper facial (VII) nerve branching and development, particularly at late embryonic and early postnatal time-points when the larger head size led to confounding background staining, we used a second transgenic line, this one carrying a bacterial artificial chromosome (BAC) containing the Shox2 gene with a lacZ insertion (previously described BAC RP23-105B3-lacZ transgenic line [37]) to visualize the facial (VII) nerves. While obvious facial (VII) nerve truncations were difficult to visualize at E11.5 (Figure 3a, b), the main branch of the facial (VII) nerve was noticeably truncated, as the smaller ganglionic projections were absent at E12.5 in Nestin-Cre; Shox $2^{\text {flox/- }}$ mutant embryos as compared to controls (Figure 3c-d, arrow). Furthermore, consistent with our neurofilament staining, at later embryonic (E13.5 and E14.5) and early postnatal (P0) stages, the zygomatic, temporal, superior buccolabial, inferior buccolabial and marginal mandibular nerve branches of the facial (VII) nerve were observed in controls (Figure 3e, g, i) and appeared truncated or absent in Nestin-Cre; Shox $2^{f l o x /}$ mutant animals (Figure 3f, h, j; arrows). For example, by P0 the facial (VII) nerves appeared to be absent in Nestin-Cre; Shox $2^{\text {flox/- }}$ mutant animals (Figure 3j, arrows). The buccal and superficial masseter nerves, both sensory components originating from the trigeminal $(\mathrm{V})$ nerve [36], were the only nerves visible in Nestin-Cre; Shox $2^{\text {flox/- }}$ mutant animals, leaving the face almost completely devoid of innervation (Figure $3 \mathbf{j}$, arrows). To determine whether the facial (VII) nerve disruptions occurred as a result of the slight reduction in Shox 2 expression in the embryonic facial mesenchyme (Additional file 3: Figure S3A-B, arrows), or whether this was related specifically to disruptions in the facial motor nucleus, we conditionally removed Shox 2 in all neural crest derivatives using a Wnt1-Cre driver. This resulted in the complete loss of Shox2 expression in the face (Additional file 5: Figure S4A, B), and ultimately did not appear to result in any disruptions to the development of the facial (VII) nerves (Additional file 5: Figure $\mathrm{S} 4 \mathrm{C}, \mathrm{D})$. Together these results show impaired axonal projection properties of visceral motor neurons (vMNs) in the facial motor nucleus of the hindbrain in mice lacking Shox2.

\section{Loss of Shox 2 in the facial motor nucleus results in elevated apoptosis}

Since Shox2-mutant embryos and neonates display impaired axonal projection properties and were unable to nurse properly, we next wanted to determine if development of the facial motor nucleus was disrupted in the absence of Shox2. Both neurofilament and lacZ staining of P0 control and Nestin-Cre; Shox $2^{\text {floxl- }}$ or Nestin-Cre; Shox $2^{\text {lacZ/flox }}$ pup brains demonstrated that the facial motor nucleus was severely reduced in size, with disruptions in neuronal spatial organization in mice lacking Shox 2 function (Figure 4a-f, arrows; note that the Shox $2^{\text {lacz }}$ allele is a null or severely hypomorphic allele, see "Methods"). While the symmetry between the left and right facial motor nuclei appears to be relatively maintained (Figure 4c-d, arrows), the two lobes that normally comprise the facial motor nucleus are no longer present (Figure 4e-f, arrows). We next investigated whether an increase in apoptosis could account for the changes observed in the facial motor nucleus of Shox2mutant brains. We found an increase in the number of apoptotic cells present at E12.5 and E14.5 in the facial 


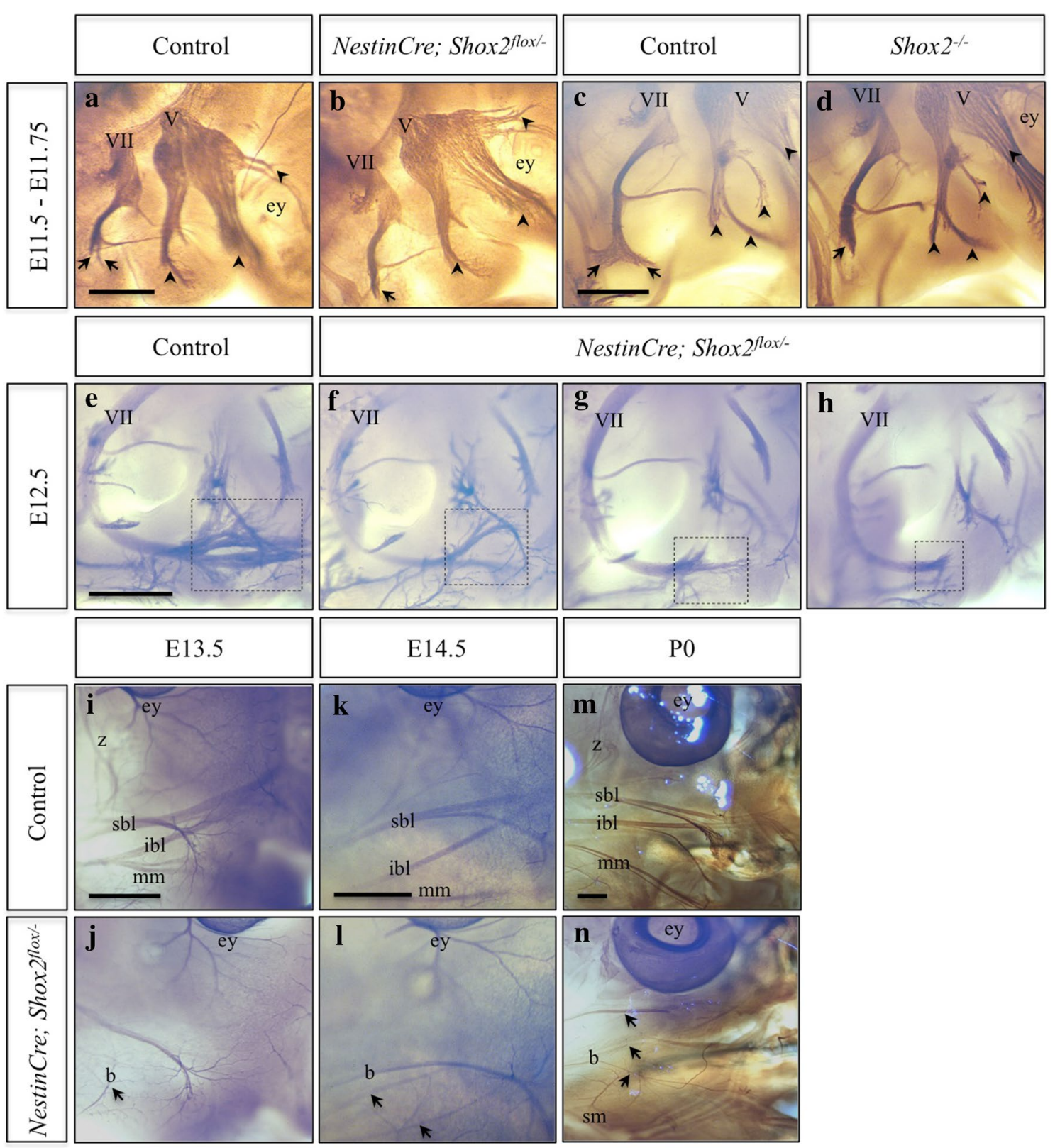

Figure 2 Facial nerve truncations in Shox2-mutant animals. a-d Side view of the E11.5 (a, b) or E11.75 (c, d) face of control (a, c), Nestin-Cre; Shox $2^{f l o x /-}(\mathbf{b})$ and Shox $2^{-1-}$ (d) embryos stained with the $2 \mathrm{H} 3$ anti-neurofilament antibody. At E1 1.5 the main branch of the facial nerve (VII) begins to separate into smaller projections in control embryos (a, arrows), while a single branch is visible in Nestin-Cre; Shox $2^{\text {flox/- }}$ conditional knockout embryos (compare $\mathbf{a}$ to $\mathbf{b}$, arrows). At E11.75 the facial nerve is noticeably truncated in the Shox $2^{-/-}$embryos (compare c to d, arrows), while the trigeminal nerve $\left(V ; \mathbf{a}-\mathbf{d}\right.$, arrowheads) remains intact. $\mathbf{e}-\mathbf{h}$ Side view of the E12.5 face of control (e) and Nestin-Cre; Shox $2^{\text {flox } /-}(\mathbf{f}-\mathbf{h})$ embryos stained with the $2 \mathrm{H} 3$ antibody display the range in severity of facial nerve truncation, with $\mathbf{f}$ being the least severe truncation and $\mathbf{h}$ being the most severe truncation observed in Nestin-Cre; Shox $2^{\text {flox/- }}$ embryos (compare e to $\mathbf{f}-\mathbf{h}$, dashed-box). (i-n) Side view of the E13.5 (i, j), E14.5 (k, I) and P0 (m, n) face of control $(\mathbf{i}, \mathbf{k}, \mathbf{m})$ and Nestin-Cre; Shox $2^{\text {flox/ }}-(\mathbf{j}, \mathbf{I}, \mathbf{n})$ animals stained with the $2 \mathrm{H} 3$ antibody. At E13.5 and E14.5 the zygomatic (z), superior buccolabial (sbl), inferior buccolabial (ibl) and marginal mandibular $(\mathrm{mm})$ nerve branches can be seen in control (i, $\mathbf{k}$ ) embryos but are not visible in Nestin-Cre; Shox ${ }^{\text {flox/- }}(\mathbf{j}, \mathbf{I})$ embryos (compare $\mathbf{i}$ to $\mathbf{j}$ and $\mathbf{k}$ to $\mathbf{I}$, arrows). At P0 the truncated remnants of what appears to be the superior buccolabial nerve were observable in Nestin-Cre; Shox $2^{\text {floxl- }}$ pups (compare $\mathbf{m}$ to $\mathbf{n}$, arrows). ey eye, b buccal nerve, sm superficial masseter nerve. Scale bar $500 \mu \mathrm{m}$. 


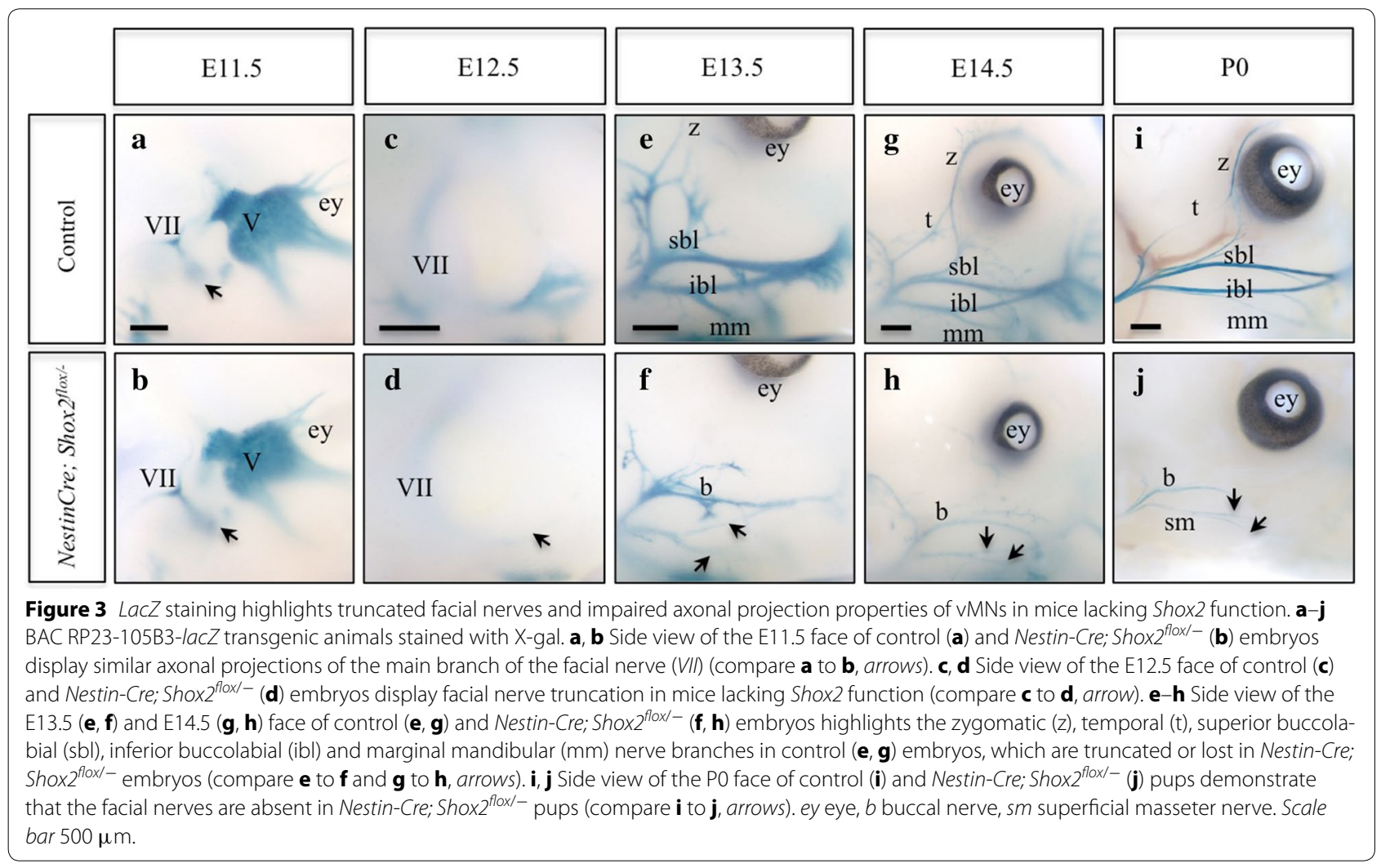

(see figure on next page.)

Figure 4 Nestin-Cre driven conditional Shox2-deletion results in disruptions in the facial motor nucleus and changes in cell death. $\mathbf{a}$, b Ventral view of the PO brain of control (a) and Nestin-Cre; Shox $2^{f l o x /-}(\mathbf{b})$ animals stained with the $2 \mathrm{H} 3$ antibody demonstrate that the facial motor nucleus ( $\left.n V I I\right)$ is severely reduced in Nestin-Cre; Shox $2^{\text {flox/ }}$ - pups (compare $\mathbf{a}$ to $\mathbf{b}$, dashed-circle and arrows). c-f X-gal staining of PO control (c, e) and Nestin-Cre; Shox $2^{l a c z \text { flox }}$ (d, f) pup brains (viewed ventrally) show Shox2 expression in the facial motor nucleus and demonstrate that the nucleus is severely reduced in size (compare $\mathbf{e}$ to $\mathbf{f}$, arrows) in mice lacking Shox2 function. Cleaved active-CASP3 immunostaining on E12.5 (g, h), E14.5 (j, k), E16.5 (m, $\mathbf{n})$ and PO $(\mathbf{p}, \mathbf{q})$ control $(\mathbf{g}, \mathbf{j}, \mathbf{m}, \mathbf{p})$ and Nestin-Cre; Shox $2^{\text {flox/- }}$ mutant $(\mathbf{h}, \mathbf{k}, \mathbf{n}, \mathbf{q})$ sagittal sections through the facial motor nucleus ( $n$ VII). i Quantification of the number of cleaved active-CASP3 + cells present in the E12.5 facial motor nucleus (see $\mathbf{g}, \mathbf{h}$ ) of control and Nestin-Cre; Shox $2^{\text {flox }-}$ embryos (plotted values are the mean \pm S.E.M, 3 sections per animals, $n=3$ animals, $p=0.0038$ ). I Quantification of the number of cleaved active-

CASP3 + cells present in the E14.5 facial motor nucleus (see $\mathbf{j}, \mathbf{k}$ ) of control and Nestin-Cre; Shox flox- $^{-}$embryos (plotted values are the mean \pm S.E.M, 3 sections per animals, $n=3$ animals, $p=0.0007$ ). $\mathbf{o}$ Quantification of the number of cleaved active-CASP3 + cells present in the E16.5 facial

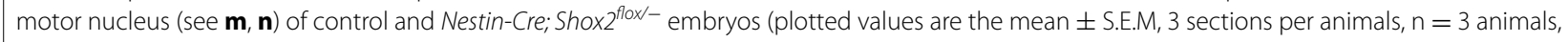
$p=0.1929$ ). $\mathbf{r}$ Quantification of the number of cleaved active-CASP3 + cells present in the PO facial motor nucleus (see $\mathbf{p}$, $\mathbf{q}$, dashed-circle) of control and Nestin-Cre; Shox $2^{\text {flox }}$ - embryos (plotted values are the mean \pm S.E.M, 3 sections per animals, $n=3$ animals, $p=0.6875$ ). $\mathbf{s}$ Quantification of the number of cleaved active-CASP3 + cells present in and around the PO facial motor nucleus (see $\mathbf{p}$, $\mathbf{q}$, entire panel including cells within the dashed-circle) of control and Nestin-Cre; Shox flox- embryos (plotted values are the mean \pm S.E.M, 3 sections per animals, $n=3$ animals, $p=0.0007$ ). t, u Representative binary particle area diagrams from ImageJ displaying Shox2lacZ + cell staining at E14.5 (t) and P0 (u) in controls and NestinCre; Shox $2^{\text {lacZ/flox }}$ facial motor nuclei. $\mathbf{v}$ Quantification of the area of Shox2lacZ + cells present in sagittal sections through the center of the E14.5 facial motor nucleus (see $\mathbf{t}$ ) of control and Nestin-Cre; Shox $2^{\text {lacz/flox }}$ embryos (plotted values are the mean \pm S.E.M, control $=3$, Nestin-Cre; Shox $2^{\text {lacz/flox }}=3$, $p=0.0027$ ). $\mathbf{w}$ Quantification of the area of Shox2lacZ + cells present in sagittal sections through the center of the P0 facial motor nucleus (see $\mathbf{u}$ ) of control and Nestin-Cre; Shox $2^{\text {lacz/flox }}$ animals (plotted values are the mean \pm S.E.M, control $=3$, Nestin-Cre; Shox $2^{\text {lacz/flox }}=3, p=0.0011$ ). cb cerebellum. a-f Scale bar $500 \mu \mathrm{m}$. $\mathbf{g}-\mathbf{q}$ Scale bar $250 \mu \mathrm{m}$.

motor nucleus of Shox2-mutants (Figure 4g-1); however, no significant increase in apoptosis was detected in the E16.5 or P0 facial motor nucleus of Shox2-mutant animals (Figure $4 \mathrm{~m}-\mathrm{r}$ ). We observed a $\sim 7.5$-fold increase in the number of cleaved active-CASP3 + cells in the E12.5 facial motor nucleus of Nestin-Cre; Shox $2^{\text {flox/- }}$ animals as compared to controls (Figure 4i; control $\mathrm{n}=3$, NestinCre; Shox $2^{\text {flox/- }} \mathrm{n}=3, \mathrm{p}=0.0038$ ). We also observed a striking $\sim 17.7$-fold increase in the number of cleaved active-CASP3 + cells in the E14.5 facial motor nucleus of 


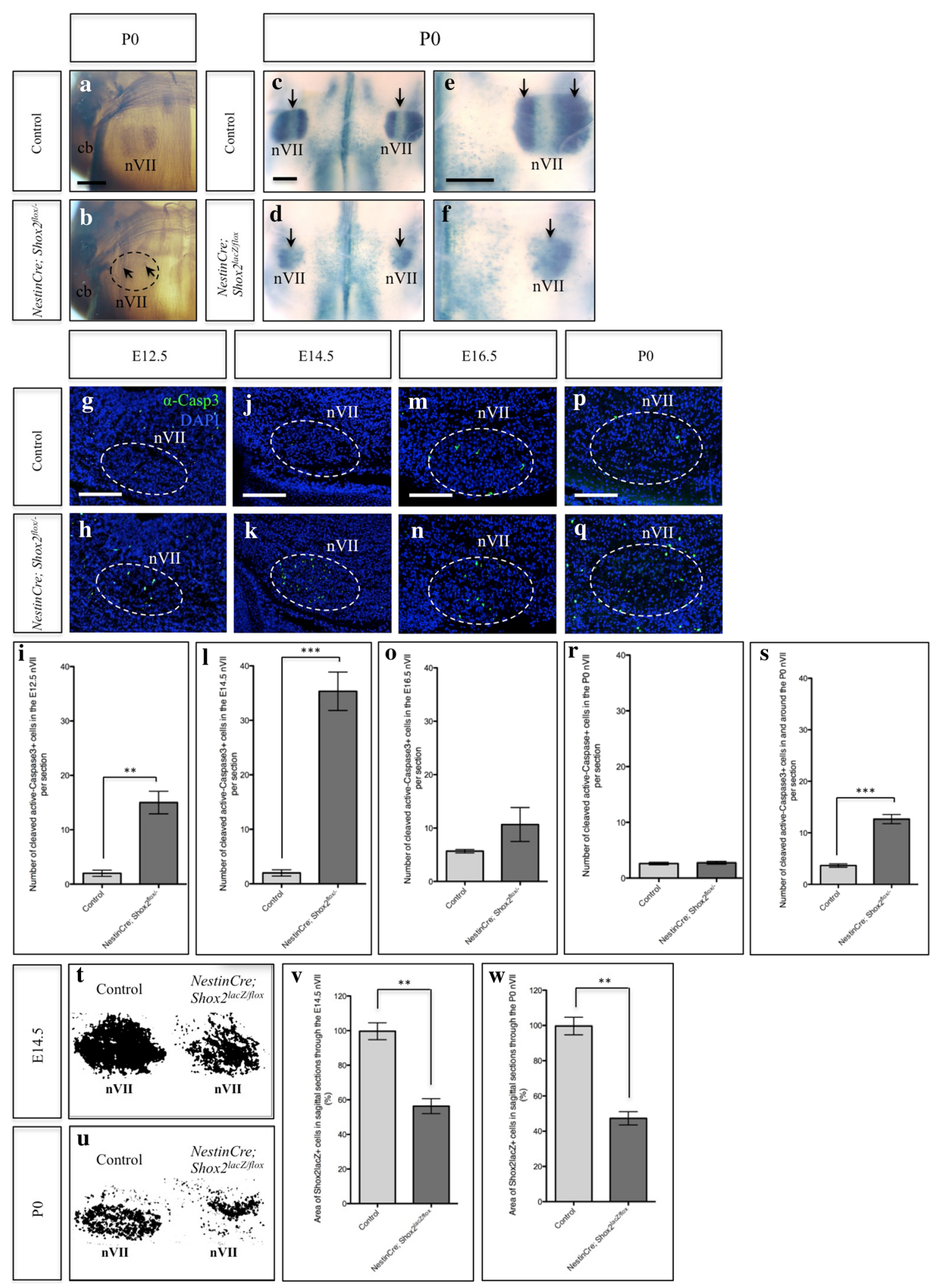


Nestin-Cre; Shox $2^{\text {flox/- }}$ animals as compared to controls (Figure 41; control $\mathrm{n}=3$, Nestin-Cre; Shox $2^{\text {flox/- }} \mathrm{n}=3$, $\mathrm{p}=0.0007)$. While the slight elevation in apoptosis detected in the E16.5 and P0 facial motor nucleus of Shox2-mutant animals was not significantly different from controls (Figure 4o, r), we did observe a 3.5-fold increase in the number of cleaved active-CASP3 + cells at P0 when we included the tissue immediately surrounding the facial motor nucleus of Nestin-Cre; Shox $2^{f l o x /}$ animals (Figure $4 \mathrm{p}-\mathrm{q}$, entire panel including cells within the dashed-circle) in our cell count (Figure 4s; control $\mathrm{n}=3$, Nestin-Cre; Shox $\left.2^{\text {flox } /-} \mathrm{n}=3, \mathrm{p}=0.0007\right)$. Moreover, when we calculated the area of Shox2lacZ + cells remaining in sagittal sections through the center of the facial motor nucleus of Nestin-Cre; Shox $2^{\text {lacz/flox }}$ animals as compared to controls at E14.5 (Figure 4t) and P0 (Figure $4 \mathrm{u}$ ), we observed a $\sim 44 \%$ decrease in the area of Shox$2 l a c Z+$ cells in the E14.5 facial motor nucleus (Figure 4v; control $\mathrm{n}=3$, Nestin-Cre; Shox $2^{\text {lacZ/flox }} \mathrm{n}=3, \mathrm{p}=0.0027$ ) and a $\sim 53 \%$ decrease in the area of Shox 2lacZ + cells in the P0 facial motor nucleus (Figure $4 \mathrm{w}$; control $\mathrm{n}=3$, Nestin-Cre; Shox $\left.2^{\text {lacZ/flox }} \mathrm{n}=3, \mathrm{p}=0.0011\right)$. Therefore, the higher levels of apoptosis are correlated with a decrease in the size of the facial motor nucleus, and taken together, the results demonstrate that apoptosis contributes to the disruptions observed in the facial motor nucleus of Nestin-Cre; Shox $2^{\text {flox/- }}$ animals.

\section{Shox2 is required for normal expression of markers of vMN identity in the facial motor nucleus}

Given the marked reduction in size of the facial motor nucleus in Shox 2 mutants (Figure 4), we next sought to investigate whether factors other than facial (VII) nerve truncation and cell death could be changing in the facial motor nucleus following the loss of Shox2. Prior to E14.5, we did not observe any obvious changes in gene expression or disruptions to the migratory patterns of vMNs (Additional file 2: Figure S2F-K, M-R). At E14.5, however, sagittal sections of the facial motor nucleus showed reductions in the overall size of the nucleus in Nestin-Cre; Shox $2^{\text {lacZ/flox }}$ embryos (Figure 5b), which was consistent with the regional increase in the number of cleaved active-CASP3 + cells at this time-point (Figure 4k). Since SHOX2 has been previously shown to regulate Isl1 [34], an important regulator of vMN development $[7,19,22]$, we next examined the expression of Isl1 in Shox2-mutant animals. We observed a regionally restricted loss of Isl1 and the hindbrain vMN determinant Phox $2 b$ in the facial motor nucleus as early as E14.5 in Nestin-Cre; Shox $2^{\text {flox/- }}$ mutant embryos as compared to controls (Figure $5 \mathrm{e}-\mathrm{h}$, arrows). Since loss of Isll function in the trigeminal and DRG have been shown to result in changes in the expression of contactin 2 (Cntn2), tubulin $\beta-3$ chain (Tubb3) and peripherin 1 (Periph) [38], and given that Phox $2 b$ deficient mice have been used to identify the facial motor nucleus as a source of Slit homolog 2 (Slit2) signaling [39], we next examined the expression patterns of these genes. Although subtle changes in the spatial patterns and expression levels of $C n t n 2$ and Tubb3 were observed, Periph1, solute carrier family 18 (Slc18a3) and Slit2 phenocopied the regionally specific absence of Isl1 and Phox $2 b$ in the facial motor nucleus at E14.5 in Nestin-Cre; Shox $2^{\text {flox/- }}$ mutant embryos (Figure $6 \mathrm{i}-\mathrm{r}$, dashed-circle and arrows). The changes in expression for these genes continued to be observed between Nestin-Cre; Shox $2^{\text {flox/- }}$ mutant embryos and controls at E16.5 (data not shown). Together, these results show that Shox 2 is required for normal expression of markers of vMN identity at E14.5.

\section{Loss of Shox 2 results in severe developmental disruptions to the facial motor nucleus}

In contrast to the subtle changes at E14.5, postnatally we observed a drastic reduction in the size of the facial motor nucleus and changes to the overall organization of motor neurons in Nestin-Cre; Shox $2^{\text {flox/- }}$ mutant animals (Figure 6), consistent with the phenotype displayed in Figure 4. Specifically, lacZ staining of P0 control and Nestin-Cre; Shox $2^{\text {lacZ/flox }}$ sagittal sections of the facial motor nucleus demonstrate that the nucleus is reduced in size in mice lacking Shox2 (Figure 6b). The expression levels of Isl1, Phox2b, Cntn2, Tubb3, Periph, Slc18a3 and Slit2 were all strikingly reduced in the P0 facial motor nucleus of Nestin-Cre; Shox $2^{\text {flox/- }}$ mutant animals as compared to controls (Figure 6e-r, dashed-circle). Since conditional inactivation of Shox 2 in the brain was previously shown to result in the down-regulation of Shh expression in dorsal-residing Purkinje cells of the cerebellum [33], we next investigated whether loss of Shox 2 function in the facial motor nucleus interfered with the expression of Shh. The expression of both Shh and patched 1 (Ptch1) were absent in the facial motor nucleus of Nestin-Cre; Shox $2^{\text {flox/- }}$ mutant animals (Figure 6s-v).

Although the loss of Shox 2 in the brain resulted in drastic reductions in the size of the facial motor nucleus and the expression of the above-mentioned genes, the spared vMNs remaining in the facial motor nucleus of Shox 2 mutants appeared to be mostly localized to the dorsal regions of the nucleus (Figure $6 B^{\prime \prime}, f, n$ ). This suggested that there could be a region-specific loss of distinct subnuclei in the facial motor nucleus in Shox2-mutant animals. Therefore we examined the expression patterns of these same genes in coronal sections of the facial motor nucleus, as this would allow us to more clearly observe the six subnuclei that comprise the main facial motor nucleus; specifically the lateral, dorsolateral, dorsal intermediate, ventral intermediate, dorsomedial and 


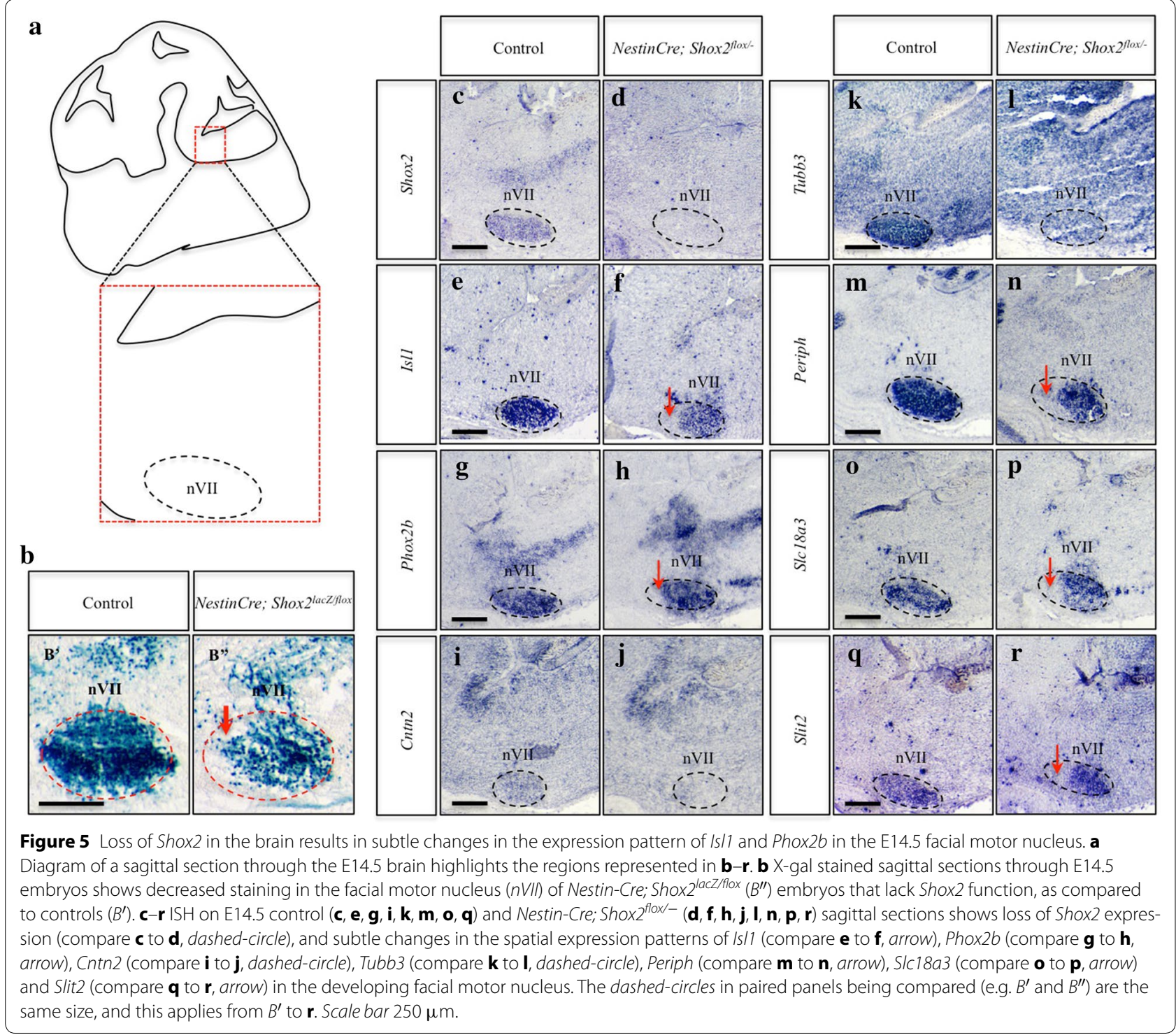

ventromedial nuclei $[23,24]$. LacZ staining of P0 control and Nestin-Cre; Shox $2^{\text {lacZ/flox }}$ coronal sections of the facial motor nucleus demonstrated that elimination of Shox 2 resulted in the loss of medially-localized subnuclei, specifically the dorsomedial and ventromedial nuclei, in addition to severe disruptions to the development of the intermediate nuclei, especially the dorsal intermediate (Figure 7b). Similar to what we observed at P0 in sagittal sections of the facial motor nucleus (Figure 6), the expression of Isl1, Phox $2 b$, Cntn2, Tubb3, Periph, Slc18a3, Slit2, Shh and Ptch1 were restricted to the lateral or intermediate regions in coronal sections of the facial motor nucleus, or completely lost in Nestin-Cre; Sho $x 2^{f l o x /-}$ mutant animals as compared to controls (Figure $7 \mathrm{e}-\mathrm{v}$, dashed-circle). While the regional changes in expression were variable between the genes examined, in general the dorsomedial, ventromedial and dorsal intermediate subnuclei of the facial motor nucleus appeared to be most strongly affected in Shox2-mutant animals (Figure 7), which may reflect a regional specific requirement for Shox 2 in the facial motor nucleus or may indicate that there are populations of vMNs within the facial motor nucleus that do not express Shox2 during development. Together, the results suggest that Shox2 is required for the development of specific subcompartments within the broader facial motor nucleus.

\section{Discussion}

In this study, we used a Nestin-Cre driver and a conditional knockout strategy to determine the contribution of Shox 2 to the development of the facial motor nucleus. We found that mice lacking Shox 2 function failed to develop 


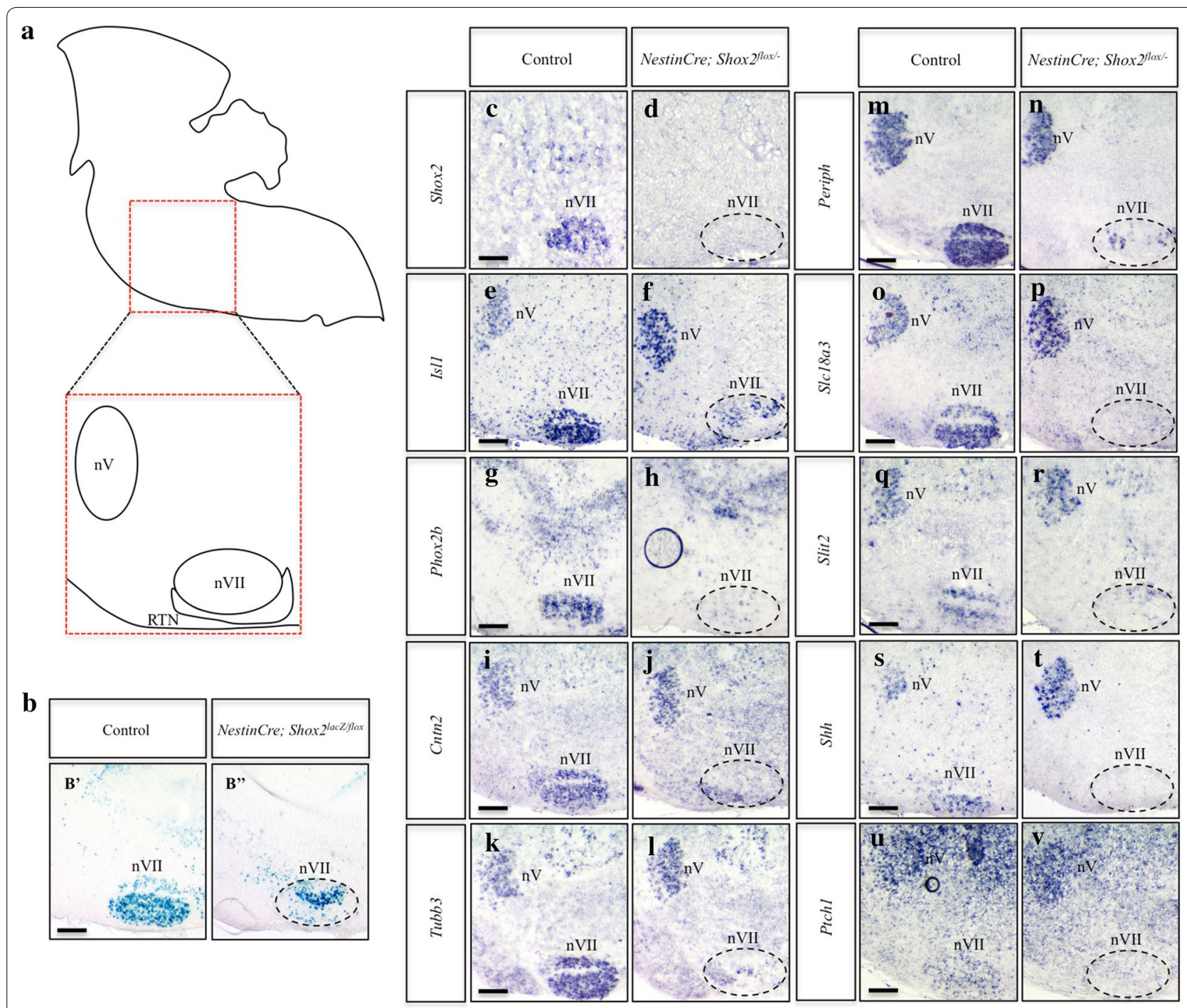

Figure 6 Shox 2 is required for the proper development of the facial motor nucleus. a Diagram of a sagittal section through the P0 brain highlights the regions represented in $\mathbf{b}-\mathbf{v}$. $\mathbf{b}$ X-gal stained sagittal sections through PO brains show a decrease in staining levels in the facial motor nucleus (nVII) of Nestin-Cre; Shox $2^{\text {lacz/flox }}\left(B^{\prime \prime}\right)$ animals as compared to controls $\left(B^{\prime}\right)$. c-v ISH on PO control (c, e, g, i, k, m, o, q, s, u) and Nestin-Cre; Shox $2^{\text {flox } /-}(\mathbf{d}$, $\mathbf{f}, \mathbf{h}, \mathbf{j}, \mathbf{l}, \mathbf{n}, \mathbf{p}, \mathbf{r}, \mathbf{t}, \mathbf{v}$ ) sagittal sections shows loss of Shox2 expression (compare $\mathbf{c}$ to $\mathbf{d}$, dashed-circle), and decreases in Is/7 (compare $\mathbf{e}$ to $\mathbf{f}$, dashedcircle), Phox2b (compare $\mathbf{g}$ to $\mathbf{h}$, dashed-circle), Cntn2 (compare $\mathbf{i}$ to $\mathbf{j}$, dashed-circle), Tubb3 (compare $\mathbf{k}$ to $\mathbf{l}$, dashed-circle), Periph (compare $\mathbf{m}$ to $\mathbf{n}$, dashed-circle), Slc18a3 (compare $\mathbf{o}$ to $\mathbf{p}$, dashed-circle), Slit2 (compare $\mathbf{q}$ to $\mathbf{r}$, dashed-circle), Shh (compare $\mathbf{s}$ to $\mathbf{t}$, dashed-circle) and Ptch1 (compare $\mathbf{u}$ to $\mathbf{v}$, dashed-circle) expression in the facial motor nucleus. $n V$ trigeminal nucleus, RTN retrotrapezoid nucleus. Scale bar $250 \mu \mathrm{m}$.

proper vMNs in the medial subnuclei normally present in the facial motor nucleus, which was accompanied by truncated or absent facial (VII) nerve projections. Our results have uncovered an unexpected and novel role for Shox2 in the development of the facial motor nucleus and facial (VII) nerves. Specifically, Shox2 is required for cell survival and perhaps plays a region-specific role in the development and/or maintenance of normal transcriptional programs of vMNs of the facial motor nucleus. Ultimately, in the absence of Shox2, pups lack facial (VII) nerves and display abnormal feeding behavior.

\section{Shox 2 is required for cell survival in the facial motor nucleus}

Nestin-Cre-mediated deletion of Shox 2 in the brain resulted in a significant increase in the number of apoptotic cells present at E12.5 and E14.5 in the facial motor nucleus of Shox2-mutants. Given that truncated and abnormal facial (VII) nerve projections could be observed in Nestin-Cre; Shox $2^{\text {flox/- }}$ mutants from E11.5 onward, apoptosis could: (1) contribute to the disruptions in the axonal projection properties of vMNs in the facial motor nucleus, or (2) result from a lack of 


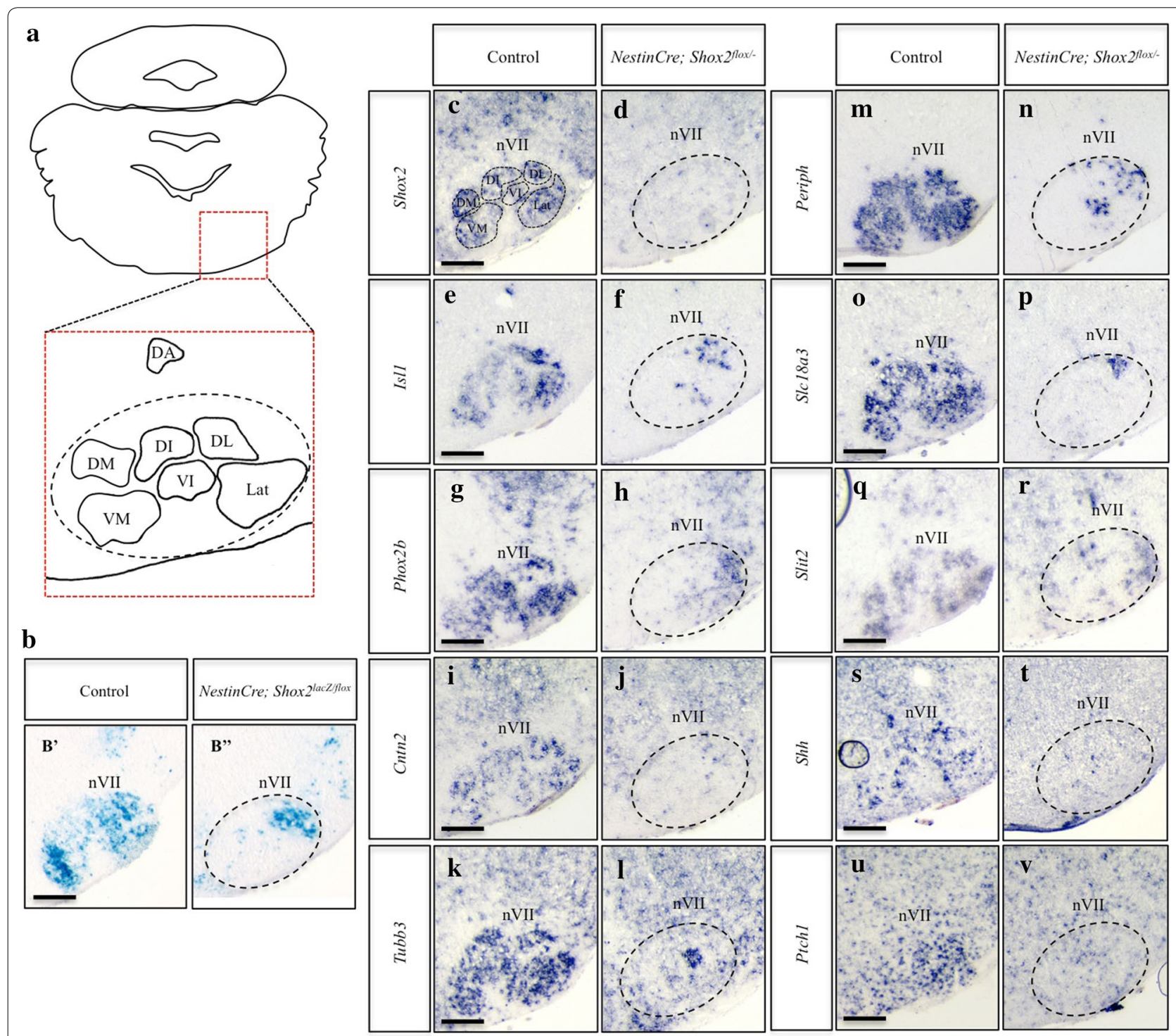

Figure 7 Loss of Shox2 function in the facial motor nucleus interferes with the proper development of the medial subnuclei. a Diagram of a coronal section through the P0 brain highlights the region represented in panels $\mathbf{b}-\mathbf{v}$, particularly the 7 neuronal clusters that form the facial motor nucleus (nVII, dashed-circle) (image adapted from [23]). b X-gal stained coronal sections through P0 brains shows a loss of medial neuronal clusters in the facial motor nucleus of Nestin-Cre; Shox ${ }^{\text {lacz/flox }}\left(B^{\prime \prime}\right)$ brains as compared to controls $\left(B^{\prime}\right)$. $\mathbf{c}-\mathbf{v}$ ISH on PO control (c, e, $\left.\mathbf{g}, \mathbf{i}, \mathbf{k}, \mathbf{m}, \mathbf{0}, \mathbf{q}, \mathbf{s}, \mathbf{u}\right)$ and Nestin-Cre; Shox $2^{\text {flox }-}-(\mathbf{d}, \mathbf{f}, \mathbf{h}, \mathbf{j}, \mathbf{I}, \mathbf{n}, \mathbf{p}, \mathbf{r}, \mathbf{t}, \mathbf{v})$ coronal sections shows loss of Shox2 expression (compare $\mathbf{c}$ to $\mathbf{d}$, dashed-circle), and decreases in /s/1 (compare e to f, dashed-circle), Phox2b (compare $\mathbf{g}$ to $\mathbf{h}$, dashed-circle), Cntn2 (compare $\mathbf{i}$ to j, dashed-circle), Tubb3 (compare $\mathbf{k}$ to $\mathbf{l}$, dashed-circle), Periph (compare $\mathbf{m}$ to $\mathbf{n}$, dashed-circle), Slc18a3 (compare o to $\mathbf{p}$, dashed-circle), Slit2 (compare $\mathbf{q}$ to $\mathbf{r}$, dashed-circle), Shh (compare $\mathbf{s}$ to t, dashedcircle) and Ptch1 (compare $\mathbf{u}$ to $\mathbf{v}$, dashed-circle) expression in the facial motor nucleus. DA dorsal accessory, DM dorsomedial, VM ventromedial, DI dorsal intermediate, VI ventral intermediate, DL dorsolateral, Lat lateral. Scale bar $250 \mu \mathrm{m}$.

peripheral trophic support for the facial (VII) nerves in Shox 2 mutants. Similarly, the changes observed in the size of the P0 facial motor nucleus also likely results from elevated cell death embryonically in Shox2-mutant animals. However, given that there are $\sim 6,400$ neurons that comprise the facial motor nucleus [23, 24], future analysis is needed to quantify cell death accurately over a developmental time course to determine if the levels of cell death we observe in Shox2-mutant animals is sufficient to account for the disruptions observed in the facial motor nucleus in the absence of Shox2. This is similar to what has been documented in Isl1 mutants, as loss of Isl1 is associated with increased cell death in the trigeminal, DRG, hindbrain and neural tube prior to E14.5, while 
later developmentally Isl1 functions during subtype specification [19, 21, 22, 38]. Accordingly, if Shox2 is required to maintain proper Isl1 expression in vMNs of the facial motor nucleus, similar to what has been observed during heart development [34], and Isl1 is required to induce the subsequent differentiation of adjacent neurons, similar to what has been observed in the neural tube [19], this could explain the elevated cell death observed in neurons adjacent to the facial motor nucleus at P0. Pattyn et al. [7] have shown that unlike PHOX2B and ISL1, NKX6 proteins (NKX6.1 and NKX6.2) are not required for the establishment of vMN identity, yet NKX6 proteins are necessary to prevent vMNs from trans-differentiating into improper neuronal subtypes. Similar to Shox2 mutants, mice lacking $N k x 6$ function display impaired axonal projection properties of $\mathrm{vMNs}$ and facial nerve disruptions [7]. Together, the Shox2-mutant model could provide an additional example to support the argument of Pattyn et al. that vMN differentiation requires multiple inputs rather than one dominant determinant [7]. Alternatively, necrosis in the facial motor nucleus region could be responsible for the observed ectopic increase in the number of apoptotic cells in tissue immediately surrounding the facial motor nucleus.

\section{Shox 2 may play a regional specific role in the transcriptional programs of vMNs during development of the facial motor nucleus}

In this study we have shown that Shox 2 is expressed in the facial motor nucleus and provide evidence that Shox 2 plays an important role during facial motor nucleus development. We have demonstrated that loss of Shox2 function results in the down-regulation or loss of Isl1, Phox2b, Cntn2, Tubb3, Periph, Slc18a3 and Slit2 in the facial motor nucleus. Since loss of Isl1 function in the trigeminal and DRG have been shown to result in changes in the expression of Cntn2, Tubb3 and Periph [38], and given that Phox2b-deficiency influences Slit2 expression [39], we propose that the observed changes in gene expression in Shox 2 mutants could result from direct or indirect regulation of Isl 1 and/or $P h o x 2 b$ by SHOX2. Since Isl1 can rescue Shox2-mediated bradycardia, and Isl1 has been shown to be a transcriptional target of SHOX2 in vitro [34], it would not be surprising if SHOX2 regulates Isl1 in the facial motor nucleus.

As conditional inactivation of Shox2 in the brain was previously shown to result in the down-regulation of Shh expression in dorsal-residing Purkinje cells of the cerebellum [33], we also investigated whether loss of Shox2 function in the facial motor nucleus interfered with expression of Shh. Similar to what was observed in the cerebellum, the expression of both Shh and Ptch1 were reduced or lost in the facial motor nucleus of Shox2-mutant animals, suggesting that Shox 2 acts upstream of SHH signaling, or that the neurons that would normally express Shh underwent apoptosis earlier embryonically in Shox2-mutant animals. Despite the known critical function of Shh in motor neuron generation [7, 11-15], the role of Shh in the later development of the vMNs of the facial motor nucleus remains largely unknown. In rats, $\mathrm{SHH}$ appears to play a role in the regeneration of the facial motor nucleus and facial (VII) nerves following nerve injury [16]. Therefore, as the facial motor nucleus normally undergoes massive cell death from E19 to P10 [24], the late-onset of Shh expression in the facial motor nucleus could be localized to specific vMNs for cell survival. This hypothesis will be tested in future studies. Together, it appears that Shox 2 is necessary for proper Isl1 and Phox $2 b$ expression levels in the developing facial motor nucleus, and is subsequently required for late-onset Shh expression; whether this results from facial (VII) nerve disruption and embryonic apoptosis in Shox2 mutants or occurs via direct or indirect regulation of Isl1, Phox $2 b$ and/or Shh has yet to be determined.

Since the phenotype observed in the facial motor nucleus of Shox 2 mutants, including the changes in gene expression, were most prominent in the medial and intermediate subnuclei, factors other than SHOX2 must contribute to the development and survival of the lateral subnuclei of the facial motor nucleus. The observed phenotype could reflect a regional specific requirement for Shox 2 in the facial motor nucleus or indicate that there are populations of vMNs within the facial motor nucleus that do not express Shox2. The latter hypothesis is supported by results depicted in Figure S2F, H, J, as the Shox 2 expression domain appears more restricted then those of Isl1 and Phox $2 b$; therefore, future analysis will be required to examine whether SHOX2-/ISL1+ and/or SHOX2-/PHOX2B + cell populations exist in the facial motor nucleus. Alternatively, if vMNs destined for the lateral subnuclei of the facial motor nucleus are specified first, this could explain why they are the least disrupted group of nuclei apparent in Shox 2 mutants. However, considering the severe disruptions to facial (VII) nerve development observed in Shox 2 mutants, including those that innervate the nasolabial musculature that are supplied by neurons located in the lateral subnuclei of the facial motor nucleus [23, 24], it is also possible that Shox2 is required for the proper development of the lateral facial motor nuclei. This is further supported by changes in the expression of Cntn2, Tubb3, Shh and Ptch1 in the lateral facial motor nucleus. Taken together, it appears that Shox2 may play a role in the transcriptional programs of vMNs during development of the facial motor nucleus; whether this occurs via a regional requirement for Shox 2 in the facial motor nucleus or influences the 
development of the entire facial motor nucleus in an equal manner has yet to be determined.

Disruptions in the development of the facial motor nucleus influences the axonal projections of vMNs of the facial (VII) nerves in Shox2-mutant animals

As Shox2-mutant neonates display impaired feeding behavior, we wondered if this was due to a loss of a subset of axons in the nerves present in the face or whether it reflected a more substantial innervation deficit. Our findings demonstrate that the loss of Shox 2 causes severe truncations and disruptions to the development of the facial (VII) nerves, which could result from: (1) a lack of peripheral trophic support for the facial (VII) nerves, (2) vMN cell death, (3) facial motor nucleus defects that influence the axonal projections of vMNs and target acquisition of the facial (VII) nerves, or a combination thereof. It should be mentioned, however, that disruptions in peripheral trophic support for the facial (VII) nerves would have to result from Shox2's autonomous function in the facial (VII) nerves themselves, and not as a result of Shox 2 playing a role as a peripheral target, since loss of Shox 2 expression in the face in Wnt1-Cre; Sho $2^{\text {flox/- }}$ mutant animals does not disrupt facial (VII) nerve development.

Given that the face of Shox2-mutant neonates are severely devoid of innervation, the behavioral abnormalities exhibited by Shox2-mutant animals could be attributed to facial paralysis. Disruption of Hoxb1 function has been shown to result in facial nerve defects in mice, where the phenotype is similar to that of human patients with Bell's Palsy or Moebius Syndrome [40]. Similarly, other Hox-mutant mouse models have displayed disruptions in facial (VII) nerve development, which correlate with facial impairments [36]. Moreover, Isl1 mutants display disruptions in the development of the facial (VII) nerves, however similar to Shox 2 mutants, early postnatal lethality has limited the behavioral analysis of these animals [21, 22, 38]. To determine if disruption to the facial motor nucleus is the cause of the early postnatal lethality of Nestin-Cre; Shox $2^{\text {flox/- }}$ animals, future studies could employ more restricted hindbrain Cre lines to specifically remove Shox 2 expression from the facial motor nucleus. If regionally restricted loss of Shox 2 in facial motor nucleus does not result in postnatal lethality, future studies could examine Shox2-mutant behavior later postnatally and in the adult to test whether Shox2mutant animals have control over their face or are experiencing facial paralysis.

\section{Conclusions}

Taken together, these results demonstrate that elimination of Shox 2 in the brain results in disruptions in the development of the facial (VII) nerves and the facial motor nucleus. The present study demonstrates that in the absence of Shox 2 the murine face develops with severe innervation deficits, ultimately highlighting the importance of Shox 2 to proper facial motor nucleus development. The Shox2-mutant model can now be exploited to further our understanding of normal neuronal development and circuit formation; processes that are likely dysregulated in human facial paralysis disorders.

\section{Methods}

\section{Mice}

To generate conditional Shox 2 knockout animals, mice bearing the Nestin-Cre transgene [35], in addition to a wild-type and deleted Shox 2 allele, were crossed to mice carrying two floxed Shox 2 alleles [25]. Shox 2 mutants were positive for Nestin-Cre and carried one deleted and one floxed Shox 2 allele. Littermate control animals carried either one or two functional copies of Shox2, as no changes in the gross morphology of the facial motor nucleus or facial nerves were observed in heterozygotes. We designated embryonic day 0.5 (E0.5) to be noon on the day a plug was detected. Mice were maintained on a mixed C57BL/6-129/Sv background. Mice carrying the deleted and floxed Shox2 alleles were described previously [25], while mice carrying the Nestin-Cre transgene were from the Jackson Laboratory (Bar Harbor, ME), and described previously [35]. BAC RP23-105B3-lacZ transgenic animals were described previously [37], while Shox $2^{\text {lacZ }}$ mice are described below. All experiments performed at the University of Calgary were approved by the Life and Environmental Sciences Animal Care Committee. Experiments were conducted on three embryos or neonates of a particular genotype at each gestational and postnatal time point described, unless otherwise stated.

\section{Generation and characterization of Shox $2^{\text {lacz }}$ mice}

Shox $2^{\text {lacZ }}$ mice were produced by pronuclear injection of a $15.4 \mathrm{~kb}$ NarI fragment (Additional file 1: Figure S1A) of BAC RP23-103D17-lacZ that has a lacZ cassette inserted in the Shox2 gene as previously described [37]. One of seven transgenic lines carrying this transgene showed an unexpected expression pattern that recapitulated all of the expression domains of the endogenous Shox 2 gene (compare Additional file 1: Figure S1D-S1E), despite evidence that the regulatory regions controlling expression in most of these domains is not within the transgene sequence [37]. This result suggested that the transgene in this line, designated Shox $2^{\text {lac } Z}$ may have inserted into the Shox 2 locus. Although rare, targeting of transgenic constructs generated by pronuclear injection has been reported [41, 42]. We confirmed a loss of Shox 2 function 
by a complementation test and targeting was shown by long range PCR (Additional file 1: Figure S1B). For the former, the Shox $2^{l a c Z}$ allele was combined with the Shox $2^{-}$allele. Mice with the genotype Shox $2^{\text {lacZ/- }}$ died at birth with defects similar to Shox2 null animals, showing non-complementation (the limb and palate phenotypes are shown in Additional file 1: Figure S1F-K, respectively). Long-range PCR was performed with a forward primer corresponding to a sequence $4.5 \mathrm{~kb}$ upstream of Shox2 (327 bp upstream of the $5^{\prime}$ limit of the transgene) and a reverse primer within the lac $Z$ sequence. These primers amplified a $5.2 \mathrm{~kb}$ PCR product from DNA of Shox $2^{\text {lacZ }}$ mice as expected if the transgene were inserted at the Shox2 genomic locus (Additional file 1: Figure S1B). Furthermore, western blotting failed to detect SHOX2 protein in lysates from E11.5 limb buds of Shox$2^{\text {lacz/lacZ }}$ embryos while lysates from wild-type littermate embryos showed clear SHOX2 signal (data not shown). Therefore we conclude that the Shox $2^{\text {lacZ }}$ allele is a null or severely hypomorphic allele. The precise molecular nature of the transgene insertion at its $3^{\prime}$ end has not yet been determined.

\section{X-gal staining}

Embryos with lacZ transgenes were stained with X-gal according to standard techniques [43]. ImageJ was used to determine the relative size of the facial motor nucleus in lacZ stained control and NestinCre; Shox $2^{\text {lacZ/flox }}$ sagittal sections at E14.5 and P0 (Figure 4t-u).

\section{In situ hybridization}

Whole-mount in situ hybridization (WISH) with a riboprobe was previously described [44]. In situ hybridization (ISH) on cryosections was previously described [25]. The Shox2 [43], Shh [45] riboprobes have been described elsewhere. PCR primers used for generating the Ptch1 riboprobe are as follows: Fwd: GGGAGGAAATGCTGAATAAAGCC and Rev: CCAGGAGGAAGACATCATCCACAC, while the primers used for generating the Isl1, Cntn2, Tubb3, Periph, Slc18a3, Phox2b, and Slit2 riboprobes were obtained from the Allen brain atlas website (http://www.brain-map.org). DIG labeled riboprobes were detected with an AP-conjugated anti-DIG antibody (Roche) and BM Purple AP (Roche) was used as the color development substrate. All samples/slides used for comparisons were processed together. Following staining, tissue sections were mounted using Aqua Poly/ Mount (Polysciences Inc.). ISH images were taken with a Leica MZ12.5 stereomicroscope using the associated Leica software. Brightness and/or contrast of the entire image was adjusted using Adobe Photoshop CS5.1 if deemed appropriate.

\section{Immunohistochemistry}

Dissected embryos and postnatal brains were placed in ice-cold PBS, and fixed in 4\% paraformaldehyde (PFA) overnight at $4^{\circ} \mathrm{C}$. The tissue was washed in PBS and equilibrated in $30 \%$ sucrose $/ \mathrm{PBS}$ overnight at $4^{\circ} \mathrm{C}$. Both embryos and postnatal brains were embedded in Tissue Freezing Medium (TFM, Triangle Biomedical Sciences) and cryosectioned (16-20 $\mu \mathrm{m}$ sections). For immunohistochemistry (IHC), cryosections were rehydrated in PBS, washed with PBT (0.1\% Triton-X), blocked using 5\% normal goat serum (NGS) for $2 \mathrm{~h}$ at room temperature, and exposed to anti-active Caspase-3 (1:400, BD Pharmingen or 1:500, Promega) at $4^{\circ} \mathrm{C}$ overnight. Slides were then washed with PBT and exposed to secondary antibody (1:200, alexa 488 goat-anti-rabbit, Life Technologies) for $2 \mathrm{~h}$ at room temperature. Sections were mounted using Aqua Poly/Mount (Polysciences Inc.). Fluorescent IHC images were captured on a Zeiss LSM710 confocal microscope.

\section{Neurofilament staining}

Antibodies recognizing neurofilaments $(2 \mathrm{H} 3)$ were used to visualize nerves in embryos or postnatal day 0 (P0) pup heads (skin was removed at P0). Samples were fixed at least $4 \mathrm{~h}$ in Dent's fixative (4:1, Methanol:DMSO). Embryos and P0 heads were processed according to standard techniques previously described [26]. The 2H3 antibody was developed by T. Jessell/J. Dodd [46] and was obtained from the Developmental Studies Hybridoma Bank developed under the auspices of the NICHD and maintained by The University of Iowa, Department of Biology, Iowa City, IA 52242.

\section{Quantification methods and statistical analysis}

Quantitative results for cell counts are represented by mean scores \pm S.E.M. and were analyzed by two-tailed unpaired $t$ tests using Prism 3 for Macintosh (GraphPad Software, La Jolla, CA, USA). 


\section{Additional files}

Additional file 1: Figure S1. Shox $2^{\text {lacz }}$ transgenic analysis. (A) Schematic of the $15.4 \mathrm{~kb}$ Shox2-LacZ transgene (above) and the endogenous Shox2 genomic locus (below). The five exons are shown as vertical boxes; red indicates the coding portion of the exons and unfilled regions indicate the untranslated regions (UTRs). Green boxes/arrows indicate the sequences and sizes (in basepairs) amplified by PCR in panels B and C. The 5,200 bp PCR product amplified from genomic DNA of Sho $\times 2^{\text {lacz }}$ mice (panel B) provides evidence for targeting via homologous recombination at the $5^{\prime}$ end of the gene (dotted lines). The forward primer for this PCR is $327 \mathrm{bp}$ upstream of the transgene sequence and the reverse primer is within the lac $Z$ cassette (blue). The $3^{\prime}$ insertion site has not yet been characterized. (B) Long range PCR demonstrating location of the transgene at the Shox2 locus, as shown by the $5.2 \mathrm{~kb}$ PCR product in five mice carrying the transgene but not in wild-type controls. (C) Genotyping of Shox ${ }^{\text {lacz }}$ mice. The wild-type allele is indicated by the $705 \mathrm{bp}$ band and the transgene insertion is detected by the 392 band, with both bands amplified in heterozygote animals. The two lanes at right have only the lower band, indicating that homozygous Shox $2^{\text {laczlacz }}$ mice do not have an intact exon 1 in their genomes, which further supports targeting at the Shox 2 locus. (D) WISH for Shox2 at E12.5. (D'-D"') ISH for Shox2 on E12.5 brain sections. (E) X-gal staining of an E12.5 Shox $2^{\text {lacz/t }}$ embryo and corresponding brain sections $\left(E^{\prime}-E^{\prime \prime \prime}\right)$. $D^{\prime}$ and $E^{\prime}$ are located anterior to $D^{\prime \prime \prime}$ and $E^{\prime \prime \prime}$. (F-I) Forelimb $(F, G)$ and hindlimb $(H, I)$ skeletons of newborn Shox $2^{\text {lacz/- }}$ mice $(G, I)$ and controls $(F, H)$ showing reduction in the humerus $(h)$ and femur $(f)$ as those found in Shoxz-null mice. (J, K) Hematoxylin and eosin (H\&E) stained coronal sections through the palate of newborn Shox $2^{\text {laczl- }}$ mice (K) and controls (J) displays a cleft palate (compare J to K, dashed-box and arrow) similar to what is found in Shox2-null mice. Abbreviations: ey, eye; tg, trigeminal; di, diencephalon; mes, mesencephalon; hb, hindbrain; drg, dorsal root ganglia; nt, neural tube; fl, forelimb; hl, hindlimb; sc, scapula; r, radius; $u$, ulna; a, autopod; pg, pelvic girdle; t, tibia; fi, fibula; PS, palate shelf Additional file 2: Figure S2. Conditional removal of Shox2 using Nestin-Cre does not result in disruptions to the migratory programs of vMNs. (A) Diagram of a transverse section through rhombomere 4 (r4) of the E11 brain highlights progenitors (red arrow, known to be Phox $2 b+[18]$ ) and post-mitotic neurons (black arrow, region known to be Phox2b +//s/1 + [18]) adjacent to the floor plate (fp) (image adapted from Pattyn et al. [18]). (B) ISH for Shox2 on an E11 transverse brain section through rhombomere 4 shows Shox2 expression in post-mitotic neurons (black arrow) but not in progenitors (red arrow). (C-E) ISH images from the Allen Brain Atlas database (http://www. brain-map.org) show Shox2 (C, http://developingmouse.brainmap. org/experiment/siv?i1 00082467\&imageld = 101400047\&initlmage $=\mathrm{ish})$, Is/7 ( $\mathrm{D}$, http://developingmouse.brain-map.org/experiment/ siv? id $=100029096$ \&imageld $=100647957$ \&initlmage $=$ ish) and Phox2b (E, http://developingmouse.brain-map.org/experiment/siv?id=1000778 06\&imageld $=101287085$ \&init/mage $=$ ish) expression in vMNs in sagittal sections at E11.5 (red arrows point to Phox $2 b+$ vMNs adjacent to the ventricular zone). (F-K) ISH on E11.5 serial sagittal sections through the

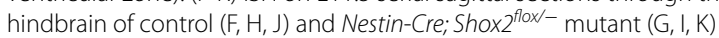
embryos shows loss of Shox 2 expression in the brain (compare F to G, arrows), while Is/1 (compare $\mathrm{H}$ to I, arrows) and Phox 26 (compare J to $\mathrm{K}$, arrows) expression is maintained in neurons migrating from the approximate rhombomere $4 / 5(\mathrm{r} 4 / \mathrm{r} 5)$ boundary to rhombomere $6(\mathrm{r} 6)$, depicted using a red-dashed line. (L) Image of an E11.5 hindbrain sagittal section available from the Allen Brain Atlas database (http://atlas.brain-map.org/ atlas?atlas $=181275741$ \#atlas $=181275741 \&$ plate $=100425904 \&$ structure $=126651910 \& \mathrm{x}=5432 \& \mathrm{y}=2371 \& \mathrm{zoom}=-2 \&$ resolution $=3.96 \& \mathrm{z}=6)$ indicates rhombomere divisions ( $r 2$ to $r 7$ ) within the pontomedullary hindbrain (PMH). (M-R) ISH on E12.5 serial sagittal sections through the hindbrain of control $(\mathrm{M}, \mathrm{O}, \mathrm{Q})$ and Nestin-Cre; Shox $2^{\text {flox }}-$ mutant $(\mathrm{N}, \mathrm{P}$, R) embryos shows loss of Shox2 expression in the brain (compare $M$ to $\mathrm{N}$, arrow), while $/ s / 7$ (compare $\mathrm{O}$ to $\mathrm{P}$, arrow) and Phox $2 b$ (compare $\mathrm{Q}$ to $R$, arrow) expression remain (approximate $r 5 / 6$ boundary depicted using a red-dashed line). (S) Image of an E13.5 hindbrain sagittal section available from the Allen Brain Atlas database (http://atlas.brainmap.org/ atlas?atlas $=181276130 \#$ atlas $=181276130 \&$ plate $=100793031 \&$ struc- ture $=111220768 \& \mathrm{x}=4931 \& \mathrm{y}=2197 \&$ zoom $=-2 \&$ resolu tion $=3.96 \& z=6$ ) indicates rhombomere divisions ( $r 5$ to $r 7$ ). Scale $\mathrm{bar}=500 \mu \mathrm{m}$

Additional file 3: Figure S3. Conditional removal of Shox 2 using Nestin-Cre does not result in disruptions in palate development. (A, B) WISH on E12.5 control (A) and Nestin-Cre; Shox $2^{\text {flox }-}$ mutant (B) embryos shows loss of Shox2 expression in parts of the developing trigeminal (V) ganglion (arrow), in addition to the developing maxillary process ( $\mathrm{mp}$, arrow) and mandibular arch (ma, arrow) in Nestin-Cre; Shox $2^{\text {flox/- }}$ mutants as compared to controls. (C, D) ISH on E12.5 sagittal sections through the hindbrain of control (C) and Nestin-Cre; Shox $2^{\text {floxl- }}$ mutant (D) embryos shows loss of Shox2 expression in the brain, including the facial motor nucleus (nVII, dashed-circle). (E) Representative image of PO control (left) and Nestin-Cre; Shox2 flox/- mutant (right) pups shows Nestin-Cre; Shox2 $2^{\text {flox/- }}$ animals with less milk in their stomachs as compared to controls (red arrows). (F-I) Coronal sections through the palate of control $(\mathrm{F}, \mathrm{H})$ and Nestin-Cre; Shox $2^{\text {flox- }}$ (G, I) pups demonstrate that Nestin-Cre; Shox $2^{\text {flox- }}$ animals have an intact palate (compare $\mathrm{F}$ to $\mathrm{G}$ and $\mathrm{H}$ to $\mathrm{l}$, arrows). $\mathrm{F}$ and $\mathrm{G}$ are rostral sections, while $\mathrm{H}$ and I are more caudal sections through the palate. (J, K) Representative PO control (J) and Nestin-Cre; Shox $2^{\text {flox/ }}-(\mathrm{K})$ pup palates (viewed ventrally) show that Nestin-Cre; Shox $2^{\text {flox }-}$ mutant animals have an intact palate. Abbreviations: ey, eye; cb, cerebellum; PS, palate shelf; PP. Scale bar $=500 \mu \mathrm{m}$

Additional file 4: Movie 1. Representative video of a PO control and Nestin-Cre; Shox $2^{\text {flox/ }}$ - mutant pup. This video highlights the different levels of physical activity of NestinCre-Cre; Shox $2^{\text {flox/- }}$ mutant pups (which are less active and display tremors) as compared to control pups, in addition to demonstrating that NestinCre-Cre; Shox flox/- mutant pups have very little milk in their stomachs as compared to controls

Additional file 5: Figure S4. Conditional removal of Shox2 using Wnt1-Cre does not influence axonal projection properties of vMNs. (A, B)

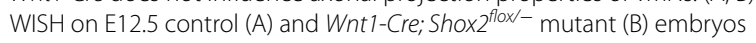
show loss of Shox2 expression in the developing trigeminal (V) ganglion, in addition to the developing maxillary process ( $\mathrm{mp}$ ) and mandibular $\operatorname{arch}(\mathrm{ma})$. (C, D) Side view of the E12.5 face of control (A) and Wnt1-Cre; Shox $2^{f l o x}-$ mutant (B) embryos stained with the $2 \mathrm{H} 3$ anti-neurofilament antibody show intact facial nerves (VII). Abbreviations: ey, eye. Scale $\mathrm{bar}=500 \mu \mathrm{m}$

\section{Authors' contribution}

JMR, DMK and JC conceived and designed the experiments. JMR performed the experiments and prepared the manuscript. JMR, DMK and JC edited the manuscript. All authors read and approved the final manuscript.

\section{Author details}

1 Department of Biological Sciences, University of Calgary, 2500 University Drive N.W., BI286D, Calgary, AB T2N 1N4, Canada. ${ }^{2}$ Department of Medical Genetics, Alberta Children's Hospital Research Institute, University of Calgary, 3330 Hospital Drive N.W., Room HS2275, Calgary, AB T2N 4N1, Canada.

\section{Acknowledgements}

The authors thank C. Schuurmans and N. Klenin for the $\alpha$-Caspase3 antibody, S. Neufeld for the Ptch 1 in situ probe, S. Abassah-Oppong and I. Skuplik for BAC RP23-105B3-lacZ mice and embryos, B. Bobick for Wnt1Cre; Shox $2^{+/}$animals and assistance during the analysis of the Shox $2^{\text {lacz }}$ transgenic line, S. Pattar and C. Ostler for their contributions to the analysis of the Shox $2^{\text {lacz }}$ transgenic line, R. Hampton for animal care, and D. Hansen, E. Turner and T. Cox for critical discussion. J.C is supported as an Alberta Heritage Foundation for Medical Research (AHFMR) Scholar. J.M.R. is supported by fellowships from NSERC and the CIHR Training Program in Genetics, Child Development and Health at the University of Calgary. D.M.K is supported by the Canadian Institute of Health Research (CIHR). This work was supported by the Canadian Institute of Health Research (CIHR) (MOP-93562).

\section{Compliance with ethical guidelines}

\section{Competing interests}

The authors declare that they have no competing interests. 
Received: 9 March 2015 Accepted: 12 June 2015

Published online: 09 July 2015

\section{References}

1. Lumsden A, Keynes R (1989) Segmental patterns of neuronal development in the chick hindbrain. Nature 337:424-428

2. Herrup K, Diglio TJ, Letsou A (1984) Cell lineage relationships in the development of the mammalian CNS. I. The facial nerve nucleus. Dev Biol 103:329-336

3. Gavalas A, Ruhrberg C, Livet J, Henderson CE, Krumlauf R (2003) Neuronal defects in the hindbrain of Hoxa1, Hoxb1 and Hoxb2 mutants reflect regulatory interactions among these Hox genes. Development 130:5663-5679

4. Gaunt SJ, Krumlauf R, Duboule D (1989) Mouse homeo-genes within a subfamily, Hox-1.4, -2.6 and -5.1, display similar anteroposterior domains of expression in the embryo, but show stage- and tissue-dependent differences in their regulation. Development 107:131-141

5. Dolle P, Lufkin T, Krumlauf R, Mark M, Duboule D, Chambon P (1993) Local alterations of Krox-20 and Hox gene expression in the hindbrain suggest lack of rhombomeres 4 and 5 in homozygote null Hoxa-1 (Hox-1.6) mutant embryos. Proc Natl Acad Sci USA 90:7666-7670

6. Studer M, Lumsden A, Ariza-McNaughton L, Bradley A, Krumlauf R (1996) Altered segmental identity and abnormal migration of motor neurons in mice lacking Hoxb-1. Nature 384:630-634

7. Pattyn A, Vallstedt A, Dias JM, Sander M, Ericson J (2003) Complementary roles for Nkx6 and Nkx2 class proteins in the establishment of motoneuron identity in the hindbrain. Development 130:4149-4159

8. Tsuchida T, Ensini M, Morton SB, Baldassare M, Edlund T, Jessell TM et al (1994) Topographic organization of embryonic motor neurons defined by expression of LIM homeobox genes. Cell 79:957-970

9. Auclair F, Valdes N, Marchand R (1996) Rhombomere-specific origin of branchial and visceral motoneurons of the facial nerve in the rat embryo. J Comp Neurol 369:451-461

10. Garel S, Garcia-Dominguez M, Charnay P (2000) Control of the migratory pathway of facial branchiomotor neurones. Development 127:5297-5307

11. Traiffort E, Charytoniuk D, Watroba L, Faure H, Sales N, Ruat M (1999) Discrete localizations of hedgehog signalling components in the developing and adult rat nervous system. Eur J Neurosci 11:3199-3214

12. Jessell TM (2000) Neuronal specification in the spinal cord: inductive signals and transcriptional codes. Nat Rev Genet 1:20-29

13. Briscoe J, Chen Y, Jessell TM, Struhl G (2001) A hedgehog-insensitive form of patched provides evidence for direct long-range morphogen activity of sonic hedgehog in the neural tube. Mol Cell 7:1279-1291

14. Briscoe J, Pierani A, Jessell TM, Ericson J (2000) A homeodomain protein code specifies progenitor cell identity and neuronal fate in the ventral neural tube. Cell 101:435-445

15. Ericson J, Morton S, Kawakami A, Roelink H, Jessell TM (1996) Two critical periods of Sonic Hedgehog signaling required for the specification of motor neuron identity. Cell 87:661-673

16. Akazawa C, Kohsaka S (2007) In vivo characterization of sonic hedgehog in the peripheral nerve regeneration. Brain Nerve 59:1341-1346

17. Dubreuil V, Hirsch MR, Pattyn A, Brunet JF, Goridis C (2000) The Phox2b transcription factor coordinately regulates neuronal cell cycle exit and identity. Development 127:5191-5201

18. Pattyn A, Hirsch M, Goridis C, Brunet JF (2000) Control of hindbrain motor neuron differentiation by the homeobox gene Phox2b. Development 127:1349-1358

19. Pfaff SL, Mendelsohn M, Stewart CL, Edlund T, Jessell TM (1996) Requirement for LIM homeobox gene IsI1 in motor neuron generation reveals a motor neuron-dependent step in interneuron differentiation. Cell 84:309-320

20. Thor S, Ericson J, Brannstrom T, Edlund T (1991) The homeodomain LIM protein $|s|-1$ is expressed in subsets of neurons and endocrine cells in the adult rat. Neuron 7:881-889

21. Sun Y, Dykes IM, Liang X, Eng SR, Evans SM, Turner EE (2008) A central role for Islet 1 in sensory neuron development linking sensory and spinal gene regulatory programs. Nat Neurosci 11:1283-1293
22. Liang $X$, Song MR, Xu Z, Lanuza GM, Liu Y, Zhuang T et al (2011) Is|1 is required for multiple aspects of motor neuron development. Mol Cell Neurosci 47:215-222

23. Ashwell KW (1982) The adult mouse facial nerve nucleus: morphology and musculotopic organization. J Anat 135:531-538

24. Ashwell KW, Watson CR (1983) The development of facial motoneurones in the mouse-neuronal death and the innervation of the facial muscles. J Embryol Exp Morphol 77:117-141

25. Cobb J, Dierich A, Huss-Garcia Y, Duboule D (2006) A mouse model for human short-stature syndromes identifies Shox2 as an upstream regulator of Runx2 during long-bone development. Proc Natl Acad Sci USA 103:4511-4515

26. Vickerman L, Neufeld S, Cobb J (2011) Shox2 function couples neural, muscular and skeletal development in the proximal forelimb. Dev Biol 350:323-336

27. Bobick BE, Cobb J (2012) Shox2 regulates progression through chondrogenesis in the mouse proximal limb. J Cell Sci 125:6071-6083

28. Yu L, Gu S, Alappat S, Song Y, Yan M, Zhang X et al (2005) Shox2-deficient mice exhibit a rare type of incomplete clefting of the secondary palate. Development 132:4397-4406

29. Gu S, Wei N, Yu L, Fei J, Chen Y (2008) Shox2-deficiency leads to dysplasia and ankylosis of the temporomandibular joint in mice. Mech Dev 125:729-742

30. Blaschke RJ, Hahurij ND, Kuijper S, Just S, Wisse LJ, Deissler K et al (2007) Targeted mutation reveals essential functions of the homeodomain transcription factor Shox2 in sinoatrial and pacemaking development. Circulation 115:1830-1838

31. Espinoza-Lewis RA, Yu L, He F, Liu H, Tang R, Shi J et al (2009) Shox2 is essential for the differentiation of cardiac pacemaker cells by repressing Nk2-5. Dev Biol 327:376-385

32. Scott A, Hasegawa H, Sakurai K, Yaron A, Cobb J, Wang F (2011) Transcription factor short stature homeobox 2 is required for proper development of tropomyosin-related kinase B-expressing mechanosensory neurons. J Neurosci 31:6741-6749

33. Rosin JM, McAllister BB, Dyck RH, Percival CJ, Kurrasch DM, Cobb J (2015) Mice lacking the transcription factor SHOX2 display impaired cerebellar development and deficits in motor coordination. Dev Biol 399:54-67

34. Hoffmann S, Berger IM, Glaser A, Bacon C, Li L, Gretz N et al (2013) Islet1 is a direct transcriptional target of the homeodomain transcription factor Shox2 and rescues the Shox2-mediated bradycardia. Basic Res Cardiol 108:339

35. Tronche F, Kellendonk C, Kretz O, Gass P, Anlag K, Orban PC et al (1999) Disruption of the glucocorticoid receptor gene in the nervous system results in reduced anxiety. Nat Genet 23:99-103

36. Tvrdik P, Capecchi MR (2006) Reversal of Hox1 gene subfunctionalization in the mouse. Dev Cell 11:239-250

37. Rosin JM, Abassah-Oppong S, Cobb J (2013) Comparative transgenic analysis of enhancers from the human SHOX and mouse Shox2 genomic regions. Hum Mol Genet 22:3063-3076

38. Dykes IM, Tempest L, Lee SI, Turner EE (2011) Brn3a and Islet1 act epistatically to regulate the gene expression program of sensory differentiation. J Neurosci 31:9789-9799

39. Geisen MJ, Di Meglio T, Pasqualetti M, Ducret S, Brunet JF, Chedotal A et al (2008) Hox paralog group 2 genes control the migration of mouse pontine neurons through slit-robo signaling. PLoS Biol 6:e142

40. Goddard JM, Rossel M, Manley NR, Capecchi MR (1996) Mice with targeted disruption of Hoxb-1 fail to form the motor nucleus of the VIIth nerve. Development 122:3217-3228

41. Susulic VS, Frederich RC, Lawitts J, Tozzo E, Kahn BB, Harper ME et al (1995) Targeted disruption of the beta 3-adrenergic receptor gene. J Biol Chem 270:29483-29492

42. Brinster RL, Braun RE, Lo D, Avarbock MR, Oram F, Palmiter RD (1989) Targeted correction of a major histocompatibility class II E alpha gene by DNA microinjected into mouse eggs. Proc Natl Acad Sci USA 86:7087-7091

43. Nagy A, Gertsenstein M, Vintersten K, Behringer RR (2003) Manipulating the mouse embryo: a laboratory manual, 3rd edn. Cold Spring Harbor Press, New York

44. Cobb J, Duboule D (2005) Comparative analysis of genes downstream of the Hoxd cluster in developing digits and external genitalia. Development 132:3055-3067 
45. Echelard Y, Epstein DJ, St-Jacques B, Shen L, Mohler J, McMahon JA et al (1993) Sonic hedgehog, a member of a family of putative signaling molecules, is implicated in the regulation of CNS polarity. Cell 75:1417-1430 regulation of axonal glycoprotein expression on subsets of embryonic spinal neurons. Neuron 1:105-116

Submit your next manuscript to BioMed Central and take full advantage of:

- Convenient online submission

- Thorough peer review

- No space constraints or color figure charges

- Immediate publication on acceptance

- Inclusion in PubMed, CAS, Scopus and Google Scholar

- Research which is freely available for redistribution

Submit your manuscript at

www.biomedcentral.com/submit

() Biomed Central 